\title{
Urine catecholamine levels as diagnostic markers for neuroblastoma in a defined population: implications for ophthalmic practice
}

${ }^{1}$ Mayo Clinic College of Medicine, Mayo Clinic and Mayo Foundation,

Rochester, MN, USA

${ }^{2}$ Mayo Clinic Division of Biostatistics, Mayo Clinic and Mayo Foundation, Rochester, MN, USA

${ }^{3}$ Department of Hematology/Oncology, University of Rochester, Rochester, NY, USA

${ }^{4}$ Mayo Clinic Department of Ophthalmology, Mayo Clinic and Mayo Foundation,

Rochester, MN, USA

Correspondence: BG Mohney, Mayo Clinic, Department of Ophthalmology, 200 First Street Southwest, Rochester, MN 55905, USA Tel: + 507-284-2233; Fax: + 507-284-4612 E-mail: mohney@mayo.edu

Received: 19 January 2010 Accepted in revised form: 20 July 2010

Published online: 24 September 2010
Abstract

Purpose Although elevated urinary catecholamine levels have been reported in 90-95\% of patients with neuroblastoma, more recent studies of pediatric Horner syndrome caused by an underling neuroblastoma have reported normal values at presentation. The purpose of this population-based study is to report the percentage of cases of neuroblastoma with elevated urinary catecholamine levels at presentation and to suggest a recommended work-up for cases of idiopathic pediatric Horner syndrome.

Methods The medical records of all pediatric ( $<19$ years) residents of Olmsted County, Minnesota diagnosed with neuroblastoma from 1 January 1969 through 31 December 2008 were retrospectively reviewed.

Results A total of 14 patients $<19$ years of age were diagnosed with neuroblastoma as residents of Olmsted County, Minnesota, during the 40-year study period. A total of $\mathbf{1 0}$ $(71 \%)$ of the 14 cases manifested elevated urinary catecholamine metabolites at the initial presentation. Urinary vanillylmandelic acid (VMA) levels were greater than twice the upper limit of normal in eight $(57 \%)$ of 14 cases, whereas homovanillic acid (HVA) levels were greater than two times the upper limit of normal in $10(71 \%)$ of the 14 cases. Three $(75 \%)$ of the four cases without significantly elevated urinary VMA or HVA levels were diagnosed with stage IV disease, whereas one $(25 \%)$ had stage II neuroblastoma.

Conclusion Urinary catecholamine levels were significantly elevated at presentation in $10(71 \%)$ of the 14 neuroblastoma cases during the 40 -year study period, suggesting that
SJ Smith', NN Diehl ${ }^{2}$, BD Smith ${ }^{3}$ and BG Mohney ${ }^{4}$

greater emphasis be placed on performing a thorough physical examination and obtaining warranted imaging studies in cases of idiopathic pediatric Horner syndrome. Eye (2010) 24, 1792-1796; doi:10.1038/eye.2010.125; published online 24 September 2010

Keywords: neuroblastoma; catecholamine; Horner syndrome; HVA; VMA

\section{Introduction}

Neuroblastoma is the most common extracranial solid tumor among children under the age of 5 years, with a published populationbased incidence of one in 6000 children. ${ }^{1}$

Neuroblastic tumors, derived from primordial neural crest cells, are characterized by defective catecholamine synthesis, frequently resulting in the accumulation and excretion of the catecholamine metabolites homovanillic acid (HVA) and vanillylmandelic acid (VMA).,3 Landmark papers concerning the use of urine catecholamine samples to detect neuroblastoma and related neural crest tumors have estimated that urinary levels of HVA and VMA were elevated in approximately $90-95 \%$ of cases. ${ }^{3,4}$ However, current reports regarding the detection of neuroblastoma in cases of pediatric Horner syndrome have detected normal catecholamine levels at presentation in a number of cases despite the presence of neural crest tumors., 5

The important role ophthalmologists have in the detection and management of neuroblastoma is underscored by the numerous ocular manifestations of this disease, including 
proptosis, ${ }^{1,7-9}$ periorbital ecchymosis, ${ }^{1,7-9}$ Horner syndrome, ${ }^{5,6,10-14}$ opsoclonus/myoclonus, ${ }^{15}$ ocular motility defects, ${ }^{7,16}$ ptosis, $^{16}$ and blindness ${ }^{8,17}$ Of special ophthalmic interest has been the detection of underlying neuroblastoma in cases of pediatric Horner syndrome, including the role urine catecholamine levels have in the recommended ophthalmic work-up. ${ }^{1,5,6,10-12,14,18,19}$ The purpose of this paper is to report the percentage of neuroblastoma cases presenting with elevated catecholamine levels among a cohort of patients $<19$ years diagnosed as residents of Olmsted County, Minnesota, over a defined 40-year period, and to suggest an ophthalmic work-up in cases of idiopathic pediatric Horner syndrome.

\section{Materials and methods}

The medical records of all pediatric ( $<19$ years) patients residing in Olmsted County when diagnosed with neuroblastoma from 1 January 1969 through 31 December 2008 were retrospectively reviewed. Potential cases of neuroblastoma were identified using the resources of the Rochester Epidemiology Project, a medical record linkage system designed to capture data on any patient-physician encounter in Olmsted County, Minnesota. ${ }^{20}$ The racial distribution of Olmsted County residents in 1990 was $95.7 \%$ Caucasian, 3.0\% AsianAmerican, $0.7 \%$ African-American, and $0.3 \%$ each Native American and other. The population of this county (106470 in 1990) is relatively isolated from other urban areas, and essentially all medical care is provided to residents by Mayo Clinic or Olmsted Medical Group and their affiliated hospitals.

All diagnoses were entered into the Rochester Epidemiology Project database and residency status was verified by specially trained personnel. Children not living in Olmsted County at the time of their diagnosis were excluded. Neuroblastoma was defined in this study by clinical diagnosis, based on tumor biopsy results, catecholamine levels, and other systemic findings. Data collected included age at diagnosis, tumor stage, HVA, and VMA levels at presentation, and final outcome.

\section{Results}

A total of 14 patients $<19$ years of age were diagnosed with neuroblastoma as residents of Olmsted County, Minnesota, during the 40-year study period. All 14 cases presented before the age of 5 , with a mean age at diagnosis for all 14 of 22.5 months (range, 0.4-42.6 months). Urinary VMA or HVA levels were elevated above twice the upper limit of normal in 10 (71\%) of 14 cases of neuroblastoma. Urinary VMA levels were greater than twice the upper limit of normal in $8(57 \%)$ of 14 cases, whereas HVA levels were greater than two times the upper limit of normal in $10(71 \%)$ of the 14 cases. Three $(75 \%)$ of the four cases without significant urinary VMA or HVA elevation were diagnosed with stage IV disease and died within a year of diagnosis, whereas the fourth case $(25 \%)$ had stage II

neuroblastoma and recovered.

Clinical information, including age at diagnosis, tumor stage, VMA, and HVA levels at presentation, and final outcome for all 14 patients is shown in Table 1. The adrenal gland was the primary tumor site in $10(72 \%)$ of the 14 , three $(21 \%)$ were in the abdomen, and one patient (7\%) had tumors located in both the mediastinum and thoracic spine. Eight (57\%) of the 14 tumors were diagnosed as stage IV, with two (14\%) each of stage II, III, and IVS. Seven $(88 \%)$ of the eight cases diagnosed with stage IV disease died, whereas all four cases diagnosed before 1 year of age where in remission 5 years after diagnosis. Horner syndrome and opsoclonus were not observed in this cohort.

\section{Discussion}

This population-based study found age-adjusted, clinically significant elevations of urinary VMA or HVA catecholamine levels at presentation in $10(71 \%)$ of 14 neuroblastoma cases over the 40 -year study. Urinary HVA levels were found to be elevated at greater than twice the upper limit of normal for age in 10 (71\%) of 14 cases, whereas VMA levels were similarly elevated in only eight $(57 \%)$ of the 14 neuroblastoma cases.

Neuroblastoma accounts for 8-10\% of all childhood cancers, with a gender and race-adjusted published incidence of 9.8 annual cases per million children $<15$ years. ${ }^{21}$ Prognosis is age and stage-dependent, with those diagnosed before their first birthday having superior outcomes. ${ }^{2,22-23}$ Ocular manifestations have an important role in the diagnosis and staging of this neoplasm. Orbital involvement, occasionally signaled by proptosis and periorbital ecchymosis, signals stage IV disease and is characterized by decreased length of survival, ${ }^{1,24}$ whereas Horner syndrome is more frequently associated with localized neuroblastoma and a better prognosis. ${ }^{9}$ Both advanced orbital disease and Horner syndrome can present as the first sign of neuroblastoma, emphasizing the integral role ophthalmologists have in the management of this disease. ${ }^{6,7}$

Historically, assessing urine catecholamine levels has had a principle role in the ophthalmic work-up of idiopathic pediatric Horner syndrome. $5,6,10-12,14,18,19$ Elevated urinary HVA/VMA levels have been reported in $90-95 \%$ of neural crest tumor cases, ${ }^{3,4}$ supporting the use of this test to rule out neuroblastoma. However, De Bernardi et $a^{25}$ describing a cohort of 144 patients 
Table 1 Urine catecholamine levels and clinical characteristics of 14 patients $<19$ years diagnosed with Neuroblastoma in Olmsted County, Minnesota, 1969-2008

\begin{tabular}{|c|c|c|c|c|c|c|c|c|}
\hline $\begin{array}{l}\text { Case no. (year } \\
\text { at diagnosis) }\end{array}$ & $\begin{array}{c}\text { Age at } \\
\text { diagnosis } \\
\text { (mon) }\end{array}$ & Gender & $\begin{array}{c}V M A \text { at } \\
\text { presentation }\end{array}$ & $\begin{array}{c}\text { HVA at } \\
\text { presentation }\end{array}$ & Tumor location & $\begin{array}{c}\text { F/U duration } \\
\text { (months) }\end{array}$ & $\begin{array}{l}\text { Final } \\
\text { outcome }\end{array}$ & Stage \\
\hline 1 (1969) & 42.6 & $\mathrm{~F}$ & 10.4 & 127.2 & $\mathrm{R}$ adrenal & 5.2 & Pt deceased & IV \\
\hline 2 (1970) & 21.5 & M & 106.7 & 160.0 & $\mathrm{~L}$ adrenal & 3.1 & Pt Deceased & IV \\
\hline 3 (1971) & 16.5 & $\mathrm{~F}$ & 75.0 & 82.0 & $\mathrm{~L}$ adrenal & 309.6 & Remission & IV \\
\hline 4 (1971) & 4.6 & $\mathrm{~F}$ & 312.0 & 500.0 & $\mathrm{R}$ adrenal & 454.6 & Remission & IVS \\
\hline $5(1976)^{\mathrm{a}}$ & 29.7 & $\mathrm{~F}$ & 12.9 & 22.9 & $\mathrm{~L}$ adrenal & 3.9 & Pt deceased & IV \\
\hline $6(1977)^{\mathrm{a}}$ & 34.8 & $\mathrm{~F}$ & 2.6 & 2.6 & $\mathrm{~L}$ adrenal & 8.7 & Pt deceased & IV \\
\hline $7(1981)^{a}$ & 22.5 & M & 13.6 & 17.0 & $\mathrm{~L}$ adrenal & 3.5 & Pt deceased & IV \\
\hline 8 (1987) & 29.5 & M & 48.0 & 58.6 & $\mathrm{R}$ abdomen & 9.1 & Pt deceased & IV \\
\hline 9 (1988) & 37.9 & M & 239.0 & 162.0 & $\mathrm{R}$ abdomen & 245.4 & Remission & III \\
\hline 10 (1990) & 36.2 & $\mathrm{~F}$ & 139.0 & 530.0 & Abdomen & 17.5 & Pt deceased & IV \\
\hline 11 (1993) & 31.3 & $\mathrm{~F}$ & 17.6 & 30.6 & $\mathrm{R}$ adrenal & 142.1 & Remission & III \\
\hline 12 (1997) & 4.9 & M & 67.1 & 61.0 & $\begin{array}{l}\text { Mediastinum, } \\
\text { thoracic spine }\end{array}$ & 144.0 & Remission & II \\
\hline $13(1997)^{\mathrm{a}}$ & 0.6 & $\mathrm{M}$ & 44.3 & 37.1 & $\mathrm{~L}$ adrenal & 142.9 & Remission & II \\
\hline $14(2004)$ & 0.4 & $\mathrm{~F}$ & 148.8 & 76.6 & $\mathrm{R}$ adrenal & 60.6 & Remission & IVS \\
\hline
\end{tabular}

Normal VMA/HVA levels by age as established by the Mayo Medical Laboratory: VMA: $<1$ year: $<27.0 \mu \mathrm{g} / \mathrm{mg}$ creatinine $(\mathrm{Cr}) ;>1$ year: $<18.0 \mu \mathrm{g} / \mathrm{mg}$ Cr; 2-4 years: $<13.0 \mu \mathrm{g} / \mathrm{mg}$ Cr HVA: $<1$ year: $<35.0 \mu \mathrm{g} / \mathrm{mg} \mathrm{Cr}$; $>1$ year: $<23.0 \mu \mathrm{g} / \mathrm{mg} \mathrm{Cr} ; 2-4$ years: $<13.5 \mu \mathrm{g} / \mathrm{mg} \mathrm{Cr}$.

VMA and HVA levels in bold are less than two times the upper limit of normal (as seen in LaBrosse et $a l^{4}$ ) for age.

${ }^{a}$ VMA and HVA levels less than two times the upper limit of normal.

with stage I and II neuroblastoma, found urinary VMA or HVA levels elevated to greater than two standard deviations above the upper limit of normal in only $68 \%$ of their cases. This finding is similar to that of LaBrosse et $a l^{4}$ who reported significantly lower levels of VMA excretion in patients diagnosed with stage I, II, and III disease. It is surprising that, in this study, only one patient with stage II disease demonstrated HVA and VMA levels in the normal range, whereas three (38\%) of eight cases with stage IV disease had VMA and HVA levels that were less than twice the upper limit of normal.

In 1988, Woodruff $e t a l^{6}$ recorded two cases of neuroblastoma in a cohort of 10 patients with pediatric Horner syndrome, one of which demonstrated normal urine catecholamine levels. More recently, Mahoney et $a^{5}$ reported underlying masses in six cases initially presenting with idiopathic Horner syndrome. Physical examination and imaging were used to detect all the masses, as all six cases had normal HVA/VMA levels at presentation. After surgical resection, pathologic examination demonstrated neuroblastoma in four $(67 \%)$ of the six. These reports combined with the findings of this study reinforce the current belief that urine studies alone are not sufficient to rule out neuroblastoma in cases of idiopathic pediatric Horner syndrome.

Due in part to the ineffective urine studies in their cohort, Mahoney et al suggested that Horner syndrome in any patient without a surgical history warrants brain, neck, and chest magnetic resonance imaging with and without contrast, as well as urinary catecholamine metabolite testing. However, in 2009, we conducted a population-based study of pediatric Horner syndrome, concluding that the lack of underlying neuroblastoma in our cohort, combined with other published estimates regarding the frequency of Horner syndrome caused by neuroblastoma, cast doubt on the value of extensive imaging in all cases of idiopathic pediatric Horner syndrome. ${ }^{19}$ We suggested that a thorough physical exam combined with initial urine studies was sufficient in most cases of idiopathic pediatric Horner syndrome, while imaging could be appropriately reserved for cases that demonstrated signs of worsening disease, including acquired or increasing iris heterochromia. ${ }^{19}$

It is unclear why this and other recent reports found a lower percentage of elevated urine catecholamines in patients with neuroblastoma. A possible explanation could be the lack of sensitivity of the more modern spot urine collections versus the traditional 24-h urine analysis; however, 24-h collections were predominantly used in this study, as all but one case were diagnosed before 1998. Of the three cases of stage IV disease without significantly elevated urine catecholamine levels, two were diagnosed in the late 1970's and one was diagnosed in 1981 and all three were evaluated with 24-h collections.

The findings of this and other studies ${ }^{5,6,14,25,26}$ confirm the current belief that negative urine screens in cases of idiopathic Horner syndrome in children are not sufficient to rule out underlying malignancy. The findings of recent reports of pediatric Horner syndrome ${ }^{19}$ and neuroblastoma ${ }^{26}$ suggest that greater emphasis be 
placed on the physical examination in cases of idiopathic pediatric Horner syndrome. Specifically, careful palpation of the neck, abdomen, and axilla, with close follow-up monitoring should be undertaken, especially in patients with normal urine studies. The decision to use imaging, as suggested by Mahoney et $a l,{ }^{5}$ should be made if there are signs of worsening disease, including the presence of a new neck mass or lymph adenopathy.

There are several limitations to the findings of this study, including the small sample size. It is possible that a larger study would have found elevated VMA and HVA levels in a higher percentage of patients; however, the findings of this study agree with those of larger studies, ${ }^{5,25}$ and serve to highlight the importance of care in evaluating patients with idiopathic pediatric Horner syndrome. In addition, the size of the cohort makes it impossible to reevaluate the sensitivity and specificity of urine catecholamine studies in cases of neuroblastoma with statistical accuracy. Another possible weakness of this report is the predominant use of 24-h urinary collections to analyze catecholamines as opposed to the more modern use of spot or random urine collections, possibly explaining the comparatively low percentage of significantly elevated catecholamines in neuroblastoma patients. However, LaBrosse et $a l^{4}$ also used 24-h collections to obtain their urine samples, reporting elevated catecholamines in $90 \%$ of their neural crest tumor cases.

Urine catecholamine levels were found to be significantly elevated in $10(71 \%)$ of 14 cases of neuroblastoma over a 40 -year period in this populationbased study. This finding underscores the importance of a thorough physical examination in cases of idiopathic pediatric Horner syndrome with negative urine catecholamine levels. Imaging studies should be utilized on the basis of the physical exam findings, including cases of acquired or increasing iris heterochromia or the detection of lymph adenopathy.

\section{Summary}

\section{What was known before}

- Urine catecholamine levels are elevated in $90-95 \%$ of patients with neuroblastoma. Consequently, this diagnostic test has played a central role in ruling out underlying neuroblastoma in cases of idiopathic pediatric Horner syndrome.

\section{What this study adds}

- This population-based study found clinically significant catecholamine elevations in only $10(71 \%)$ of 14 cases of neuroblastoma over a defined 40 -year period. Three of the four without significantly elevated HVA/VMA levels had stage IV disease and died. These findings underscore the importance of a thorough physical examination and warranted imaging studies in cases of idiopathic pediatric Horner syndrome.

\section{Conflict of interest}

The authors declare no conflict of interest.

\section{Acknowledgements}

Supported in part by an unrestricted grant from Research to Prevent Blindness, Inc., New York, NY.

\section{References}

1 Smith S, Diehl N, Smith B, Mohney B. Incidence, Ocular Manifestations, and Survival in Children with Neuroblastoma: A Population-Based Study. Am J Ophthalmol 2010; 149(4): 677-682.e2.

2 Castleberry RP. Biology and Treatment of Neuroblastoma. Pediatr Clin North Am 1997; 44: 919-937.

3 Laug WE, Siegel SE, Shaw KNF, Landing B, Baptista J, Gutenstein M. Initial Urinary Catecholamine Metabolite Concentrations and Prognosis in Neuroblastoma. Pediatrics 1978; 62: 77-83.

4 LaBrosse EH, Com-Nougue C, Zucker JM, Comoy E, Bohuon C, Lemerle J et al. Urinary excretion of 3-methoxy-4hydroxymandelic acid and 3-methoxy-4-hydroxyphenylacetic acid by 288 patients with neuroblastoma and related neural crest tumors. Cancer Res 1980; 40: 1995-2001.

5 Mahoney NR, Liu GT, Menacker SJ, Wilson MC, Hogarty MD, Maris JM. Pediatric Horner Syndrome: Etiologies and Roles of Imaging and Urine Studies to Detect Neuroblastoma and Other Responsible Mass Lesions. Am J Ophthalmol 2006; 142: 651-659.

6 Woodruff G, Buncic JR, Morin JD. Horner's Syndrome in Children. J Pediatr Ophthalmol Strab 1988; 25: 40-44.

7 Ahmed S, Goel S, Khandwala M, Agrawal A, Chang B, Simmons IG. Neuroblastoma with orbital metastasis: Ophthalmic presentation and role of ophthalmologists. Eye 2006; 20: 466-470.

8 Belgaumi AF, Kauffman WM, Jenkins JJ, Cordoba J, Bowman LC, Santana VM et al. Blindness in Children with Neuroblastoma. Cancer 1997; 80(10): 1997-2004.

9 Musarell MA, Chan HS, DeBoer G, Gallie BL. Ocular Involvement in Neuroblastoma: Prognostic Implications. Ophthalmology 1984; 91: 936-940.

10 Zafeiriou DI, Economou M, Koliouskas D, Triantafyllou P, Kardaras P, Gombakis N et al. Congenital Horner's Syndrome associated with cervical neuroblastoma. Eur J of Paediatric Neurology 2006; 10: 90-92.

11 Saur C, Levinsohn MW. Horner's Syndrome in Childhood. Neurology 1976; 26: 216-220.

12 Jeffery AR, Ellis FJ, Repka MX, Buncic JR. Pediatric Horner Syndrome. J AAPOS 1998; 2: 159-167.

13 Jaffe N, Cassady JR, Filler RM, Traggis D. Heterochromasia and Horner syndrome associated with cervical and mediastinal neuroblastoma. J Pediatr 1975; 87: 75-77.

14 George NDL, Gonzalez G, Hoyt CS. Does Horner's syndrome in infancy require investigation? $\mathrm{Br} J$ Ophthalmol 1998; 82: 51-54.

15 Farrelly C, Daneman A, Chan H, Martin D. Occult Neuroblastoma Presenting with Opsomyoclonus: Utility of Computed Comography. Am J Roentgenology 1984; 142: 807-810. 
16 Alfano JE. Ophthalmological aspects of neuroblastomatosis: a study of 53 verified cases. Trans Am Acad Ophthalmol Otalaryngol 1968; 72: 830-848.

17 Shubert EE, Oliver GL, Jaco NT. Metastatic neuroblastoma causing bilateral blindness. Canad J Ophthal 1969; 4: 100-103.

18 Morrison DA, Bibby K, Woodruff G. The 'harlequin' sign and congenital Horner's syndrome. J Neurol Neurosurg Psychiatry 1997; 62: 626-628.

19 Smith S, Diehl N, Leavitt J, Mohney B. Incidence of Pediatric Horner Syndrome and the Risk of Neuroblastoma: A Population-Based Study. Arch Ophthalmol 2010; 128(3): 324-329.

20 Kurland L, Molgaard CA. The patient record in epidemiology. Sci Am 1981; 245(4): 54-63.

21 Horner MJ, Ries LAG, Krapcho M, Neyman N, Aminou R, Howlader $\mathrm{N}$ et al. (eds). SEER Cancer Statistics Review, 1975-2006. National Cancer Institute: Bethesda, MD, http://seer.cancer.gov/csr/1975_2006/ (based on November 2008 SEER data submission, posted to the SEER web site, 2009).
22 Woods WG, Gao R-N, Shuster JJ, Robison LL, Bernstein M, Weitzman $\mathrm{S}$ et al. Screening of Infants and Mortality Due to Neuroblastoma. N Engl J Med 2002; 346: 1041-1046.

23 Bernstein ML, Leclerc JM, Bunin G, Brisson L, Robison L, Shuster $\mathrm{J}$ et al. A population-based study of neuroblastoma incidence, survival and mortality in North America. J Clin Oncol 1992; 10: 323-329.

24 Brodeur GM, Seeger RC, Barrett A, Berthold F, Castleberry $\mathrm{RP}, \mathrm{D}$ 'Angio $\mathrm{G}$ et al. International criteria for diagnosis, staging, and response to treatment in patients with neuroblastoma. J Clin Oncol 1988; 6: 1874-1881.

25 De Bernardi B, Conte M, Mancini A, Donfrancesco A, Alvisi P, Toma $\mathrm{P}$ et al. Localized Resectable Neuroblasotma: Results of the Second Study of the Italian Cooperative Group for Neuroblastoma. J Clin Oncol 1995; 13: 884-893.

26 Demir HA, Yalcin B, Buyukpamukcu N, Kale G, Varan A, Akyüz $C$ et al. Thoracic Neuroblastic Tumors in Childhood. Pediatr Blood Cancer 2010; 54(7): 885-889. 